\title{
LOCATION OF INDUSTRY ON MERSEYSIDE
}

$\mathrm{T}^{\mathrm{H}}$

HE Social Science Department of the University of Liverpool continues to carry on its invaluable work in war-time, and in the latest volume in the New Merseyside Series, the Statistics Division has made an important contribution to the local planning which must be undertaken within the scope of national planning principle. "The Distribution of Population and the Location of Industry on Merseyside", by W. Smith (Liverpool : University Press of Liverpool. 5s. net.), gives a clear and carefully drawn picture of the industrial features of the area as they were on the eve of the War. Mr. Smith indicates the elements of change as well as of stability, and this admirable analysis of the industrial and social pattern of Merseyside should stimulate research workers in other areas to bring up to date, so far as possible, parallel investigations in their own areas, in order to provide the factual basis for any detailed attempt to plan the post-war location of industry.

Analysing first the distribution of population, Mr. Smith points out that differential age-composition may be dismissed as definitely not responsible for the higher birth-rate of Merseyside and that the population of Merseyside would grow naturally and continuously if no other factor intervened. Since 1927 the migration curve of Merseyside, which has consistently shown an annual net exodus, has varied with the state of trade in Britain, increasing when industry and trade have been active and falling away when they have been sluggish. In regard to the local distribution of population on Merseyside, Liverpool, Bootle and Birkenhead exhibit comparable trends. Bebington, Crosby, Hoylake, Ellesmere Port and Wirral all show, after adjustments have been made for changes in boundaries, continuous inward balances of migration, while Huyton and West Lancashire both exhibited an outward migration balance prior to the War of 1914-18. The core of Merseyside is an area of high natural increase but, since 1927, of large outward migration balance and of declining population, while the margin is an area of lower natural increase, in places of natural deficit, but of large inward migration balance and of increasing population.

In regard to the location of industry, Mr. Smith points out that throughout the period 1924-39 Merseyside had less than its share of employment and more than its share of unemployment, the gap tending to increase during the period up to 1937-38 and markedly decreasing in 1938. There was a substantial recovery in the employment position on Merseyside on the eve of the War, but insufficient to make good completely the ground lost in the preceding years. Analysing the industrial character of Merseyside, it is noted that metals and engineering, other manufacturing industries and 'other services' have fluctuated widely, and these groups occupy a relatively larger place in the economy of Merseyside in times of boom and a relatively smaller place in times of depression. The reverse is true of food, drink and tobacco, and textiles and clothing, which show little fluctuation in numbers, while with regard to transport and distribution, which exhibit movements independent of the trade cycle, it appears that insured workers flock into the distributive trades in times of industrial depression and abandon them in times of industrial prosperity.
The industrial structure of Merseyside is thus not wholly static, and Merseyside presents a different industrial structure from Great Britain as a whole both in nature of industry and in size of factory. In proportion to its total employment, Merseyside has a relatively large share of large factories. Analysis of the location of individual industries, which occupies the longest chapter of the report, leads to a discussion of the general factors affecting the location of industry on Merseyside, in which it is pointed out that industries which are highly localized on Merseyside almost all depend directly on imported materials, and the primary industries have a higher location factor than the secondary products derived from them. Moreover, Merseyside has few industries using primary materials produced within Britain, and where such materials are used it is in smaller quantities than imported materials. The pull of Merseyside on industrial location in respect of materials is chiefly bound up with the materials imported through the Port of Liverpool, those of low value in proportion to weight feeling the pull most strongly.

In respect of labour, the pull of Merseyside on industrial location affects chiefly those industries requiring labour in quantity irrespective of skill, and Mr. Smith notes that the requirements of skilled labour appears to be of decreasing importance in Great Britain as a determinant of industrial location, quantity rather than quality of labcur being of significance. In regard to mobility and immobility, seed crushing, grain milling and sugar refining stand out clearly from the rest in every respect as essentially immobile. Cattle, dog and poultry foods, and to a lesser extent galvanized sheets, approach this group, while the most mobile of the industries considered are matches, telegraph and telephone apparatus, tobacco and aircraft. The major seat of industry within Merseyside is the dock and water-front zone, where all immobile industries are focused, as well as shipbuilding and repairing, constructional engineering and newsprint manufacture, all of which offer mainly male employment. In the extra-dock zone the industries show in the aggregate greater mobility and frequently provide more female than male employment.

In the third part of the report, discussing the future of population and industry in the area, the importance of such studies as providing the factual basis in reconstruction planning is well illustrated. The future magnitude of the population of Merseyside may be said to depend on the rate of natural increase-which on the whole was steady for the five years preceding the War, the extent of war casualties and of the maintenance of the armed forces after the War, the permanence of war-time evacuation and the extent of industrial migration. The future local distribution of population on Merseyside may be presumed to show a continuation or intensification of movements in progress immediately before the outbreak of the War. The future volume of industrial employment on Merseyside is likely to be profoundly affected by the trade of the Port. While the import of food through the Port of Liverpool is likely to be maintained and is unlikely to be greatly affected by changes in British agriculture, restrictions in the world's markets open to Britain are likely to have much more profound effects.

In commenting on possible dispersal of industry from the point of view of defence, Mr. Smith states that while a large agglomeration of factories is presumably an easier target for air attack than a wide 
scatter of factories over the countryside, the defence of a group of factories may be an easier problem than the defence of widely scattered units. Merseyside has claims to correct deficiencies in the provision of greater opportunities for skilled male employment and for a greater number of the new 'assembly' industries. For correct industrial balance, Merseyside needs more opportunities for skilled craftsmen, and there are many industries of this type possessing considerable mobility which might be directed to Merseyside if the central government contemplates control of industrial location. Such industries should be directed to the extra-dock zone, where the working conditions ari better, where the product of a foodstuff can be made under more hygienic conditions and where labour lives within easier access of the factory. Moreorer, as regards the industrial satellite in the Mersey. side area, if it is not to drain life from its parent, its success appears to depend on the attraction of new industries from outside Merseyside altogether.

There can be no two opinions as to the value of studies which bring out as clearly for other districts as this one does for Merseyside the factors which determine the volume of employment and local prosperity and well-being, and in their absence it can scarcely be maintained that local authorities are in possession of the knowledge which should be the foundation of their planning. Mr. Smith's report provides an admirable example of the way in which scientific method and investigation can contribute to the solution of major problems in a democratic society.

\section{AUTOMATIC PRODUCTION OF OSCILLATOR SCALES}

$\mathrm{T}$

HE frequency of an oscillator is usually set by dial adjustments corresponding to a calibration chart from which the exact frequency corresponding to the dial indications may be obtained. 'The relationships between the frequency and dial markings, moreover, are different for every oscillator, so that a calibration chart must be prepared for each. This is not particularly difficult but is laborious, by reason of the need to refer for every reading to a calibration chart. It is much simpler to employ a dial marked directly in frequencies, but to provide such a scale by usual methods requires much time and labour when the frequency range is large and the accuracy is to be high. Although the scales for different oscillators are similar, they are not suificiently alike to permit the scales for all oscillators to be printed from a single master film.

A method of printing such scales has, however, been recently developed and has been described by 'T. Slonezewski (Bell Lab. Rec., 20, No. 11, July, 1942). A master scale $A$ is used which, when placed over an unexposed film $B$, is moved with respect to $B$ at a varying rate, such that at each 50 -cycle point a line on scale $A$ will be directly over its correct position on scale $B$. The section of film $B$ is exposed at the instant it is under the corresponding line on film $A$. 'Two oscillators are used, set up facing each other, one serving as the standard and having an accurately marked film scale. The other, to be calibrated, carries on its sprocket the unexposed film that is to be marked, line by line, from the film of the standard, although the spacing of the lines will be different from the standard.

The condenser-driving spindle of each oscillator carries a worm-driven driving gear and film sprocket. For the duration of the calibration, 60-cycle synchronous motors are attached to the condenser worms of each oscillator. A standard motion-picture lamp is mounted behind the film of the standard, and a condensing lens focuses its rays in a narrow band over the section opposite the hair lines where the scale is read. The test oscillator motor receives its supply from the commercial 60-cycle supply. That on the standard is driven by a 'difference' frequency from the output of a modulator to which the output of the two oscillators is fed. When the two oscillators are 60 cycles apart, this latter motor will therefore have a 60-cycle supply, and the two films will be running at the same speed. As each line on the standard film passes through the band of light, it will be printed on the film of the test oscillator. The purpose of this drive arrangement is to vary the speed of the standard film in such a way that the line in the light beam corresponds to the frequency of the test oscillator except for the 60-cycle difference. This 60 -cycle constant difference is readily corrected after calibration by the low-frequency adjustment that has been provided for this purpose.

\section{EARTHED-PLATE AMPLIFIER FOR THE FREQUENCY-MODULATION TRANSMITTER}

IN the United States, frequency-modulation has 1 been assigned the wave band $42-50$ m.c and at these frequencies, simplification in design and reduction in size of transmitters are of particular importance because of lead reactances and stray capacitances to earth, which increase with frequency and with size, and may become serious obstacles in large transmitters operating at high frequencies.

A $10-\mathrm{kw}$. transmitter has been developed recently by the Bell Laboratories in which the difficulties have been overcome using the new Western Electric $389 A A$, air-cooled valve, and by a novel circuit arrangement due to W. H. Doherty. Even with this new tube, however, it was found that there would be sufficient stray plate-earth capacitance to result in a rather large loss in the plate-tuning coil, andof even greater importance-the tuning would be undesirably sharp.

Both these obstacles were overcome by the use of an earthed-plate amplifier and a number of novel features described by A. A. Skene (Bell Lab. Rec., 20, No. 11, July, 1942). The circuit employed results in the stray plate capacitance-to-earth being in parallel with the plate-earthing condenser, which is used to provide a radio-frequency path to earth while blocking the D.C., and thus has no effect on the operation of the plate circuit. Only the filamentto-earth capacitance remains and is very much smaller than the plate-to-earth capacitance. The filament is at a high radio-frequency potential, and it is very necessary to supply filament current without operating the filament transformer at this high potential above earth. It is also necessary to supply radio-frequency driving potential between the grid and filament from the driver unit, one side of which is earthed.

An ingenious arrangement is described which achieves these objectives. The normal plate-tuning coil is replaced in the new circuit by a coil between filament and earth, and is formed of a pair of copper 